\section{Performing Structural Design and Modeling of Transformers Using ANSYS- Maxwell}

\author{
Yıldırım ÖZÜPAK \\ Dicle University, Silvan Vocational School, Electrical and Energy Department, Diyarbakır, TURKEY
}

\section{Keywords}

Transformer design,

FEM,

ANSYS@Maxwell,

Magnetic flux.

\begin{abstract}
Transformers have attracted great interest since they have been used due to their robustness and application in power systems. Therefore, the nominal values of transformers grow even more in larger power systems due to the constantly increasing power demand. Many types of research are carried out to increase the performance characteristics of transformers and their compatibility with power systems. There are different methods and analysis tools for these studies. One of them is ANSYS@Maxwell, which performs analysis based on the Finite Element Method (FEM). With this program, the design, modeling, analysis, and performance evaluation of the transformer in a high-performance simulation environment can be achieved through effective strategic modeling. In this study, the design and modeling of a three-phase core-type transformer with coils and terminals are explained in detail in ANSYS @ Maxwell simulation platform. Besides, the transformer models examined were adapted using ANSYS@MAXWELL software based on the finite element method. Analyzes are performed to estimate the core-losses, leak-losses, DC-losses, and winding-eddy current losses-of transformers with this program. A large number of meshes were used in FEM analysis of 2D and 3D models to examine the losses in detail.
\end{abstract}

\section{Introduction}

For Power, transformers are used to step down or step up the voltage for the transmission and distribution of energy in electric power systems. Due to its high power efficiency, it is one of the most important and expensive devices with its wide application in the power system. Therefore, effective design and structural modeling are required before transformers can be used in power systems.

Transformers are generally designed with 3 legs. The high voltage (HV) coil is wound over the low voltage (LV) winding and this combination is placed on the leg. Insulation is provided between LV and HV windings [1-3]. Transformers use a concentric type of winding Once the windings are in place, the terminals must be derived from the windings to be connected in a $Y$ or format depending on the type of application required. Different methods have been developed for transformer design and modeling. One of these methods is the Finite Element Method (FEM). This method is used effectively in engineering problems [4-6]. FEM is the most powerful known method for the numerical solution of boundary and initial value problems characterized by partial differential equations. Today, it is used in almost all fields of engineering and applied science.

There are two main features of this method to be useful and successful. The first is that it divides the model into a limited number of areas [7]. Second, the boundary and initial value problems to which the method is applied are formulated in a piecewise or integral form. FEM is used effectively as a numerical method in solving complex engineering problems - today [8-12]. The basic solution logic of this method is to divide the model into a finite number of elements, integrate these elements with nodes (mesh), and make a realistic solution. With this method, the area to be analyzed is separated into multiple small sub-regions called finite elements that are connected like a mesh (mesh). The schematic diagram of the mesh three-phase core type transformer is given in Figure 1.

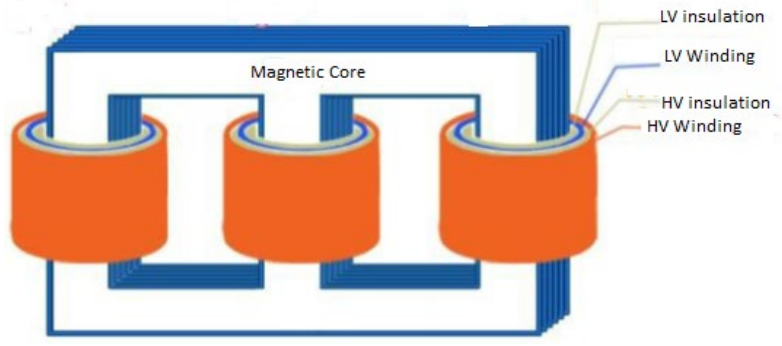

Figure 1. Model of the transformer

In this paper, the design and modeling of the transformer were carried out with the ANSYS@maxwell program, which realizes a solution based on FEM for transformer design. The designed transformer model has been verified by comparing it with the results of the real transformer model. The main purpose of this study is to reduce the cost of materials, to reduce the number of prototypes produced for experimental purposes, and to obtain the optimum model of the desired models. The method and analysis program used gave results with sufficient accuracy to verify the designed models.

\section{Structural modeling of the transformer}

\subsection{ANSYS-electromagnetic}

With the electromagnetic solvent part of the design program, transformers, motors, electromagnetic fluxes, leakage-fluxes and thermal calculations, design-and electromagnetic andelectromechanical analysis of 2- D and 3D devices including sensors and-coils are carried out. ANSYS includes many sub-analysis programs. With one of these, ANSYS @ MAXWELL, electromagnetic and electric-fields whose static frequency domain is not fixed are analyzed. This program automatically creates a suitable, efficient, and accurate network in all components of the geometry to be analyzed to solve the problem. 
The automatic adaptive meshing process takes advantage of an efficient design flow - by removing complexity from the problemsolving process. ANSYS-PExprt and ANSYS-RMxprt design platforms are also available in the ANSYS @ MAXWELL interface. An important feature of the ANSYS @ MAXWELI program is the ability to generate models from finite element-solutions for use in ANSYS-Simplorer This-property creates a powerful electromagnetic-based design flow that allows-to a combination of complex-circuits with Maxwell's correct component-models [46]. The design in ANSYS @ MAXWELI environment is like the block diagram presented in Figure 2.

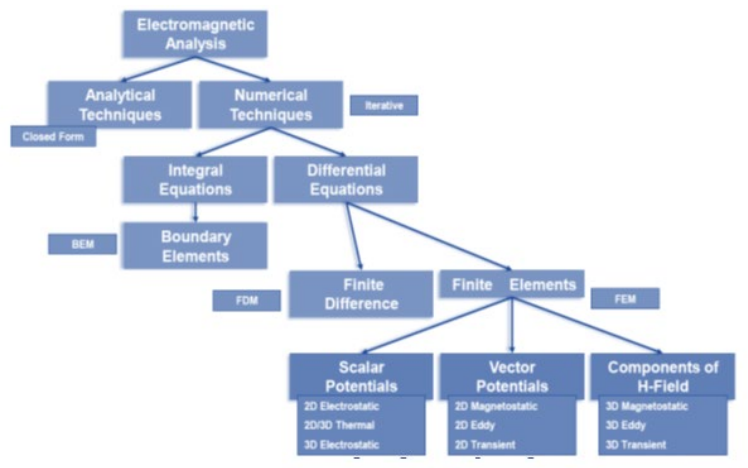

Figure 2. Block diagram of the design in ANSYS@MAXWELL

\subsection{Stages of creating a simulation model of transformer}

The transformer models examined in this study were adapted using ANSYS @ MAXWELL software based on the finite-element method. With this program, analyzes are carried out to estimate the corelosses, stray-losses, DC-losses, and winding-eddy current losses-of transformers. A large number of meshes were used in FEM analysis of 2D and 3D models to examine the losses in detail. In Figure 3, a flowdiagram of FEM modeling of transformer designed in program environment is given.

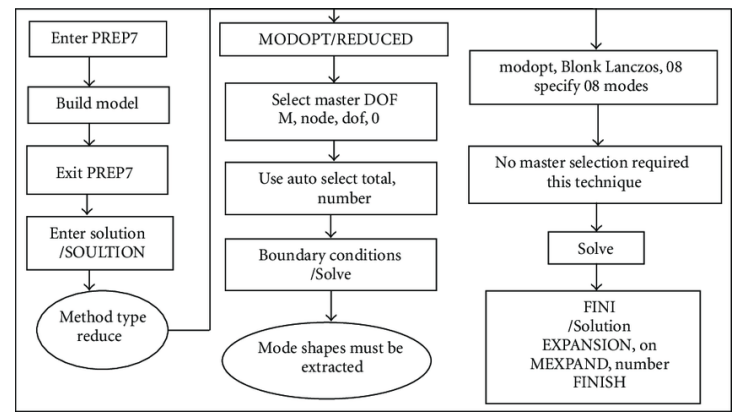

Figure 3. Step-by-step block diagram of modeling and analysis with ANSYS-Maxwell.

As with every design platform, ANSYS@MAXWELL program has its unique interface. Designs can be created in $2 \mathrm{D}$ or $3 \mathrm{D}$ in the interface of this program. A model designed in 3D can be converted directly into a 2D model and analysis can be performed. In the main menu of the program, the winding, core, terminals, and tank of the transformer can be created by following the path given in the figures below in the draw section. The templates used in the program are the templates available in the relevant library. The geometrical and electrical values of the winding or core used in the design of the transformer can be adjusted on the interface.

\subsection{Design of core}

The design of the core is done in the order given below. First, the core to be used is selected, then the geometric properties of the core are determined in the window that opens. Draw> User Define Primitive> RmExpert> Transcore is selected respectively. Modeling stages and created model examples are given in Figure 4.

\begin{tabular}{|l|l|l|l|l|l|}
\hline \multicolumn{1}{|c|}{ Name } & \multicolumn{1}{|c|}{ Value } & Unit & Evaluated... & \multicolumn{1}{c|}{ Description } \\
\hline Command & CreateUserDefinedPart & & & \\
\hline & Coordinate... & Global & & & \\
\hline Name & RMxprt/TransCore.dll & & & \\
\hline Location & syslib & & & \\
\hline & Version & 6.0 & & & \\
\hline DiaLeg & 650 & $\mathrm{~mm}$ & $650 \mathrm{~mm}$ & Outer diameter of leg cross-section \\
\hline & DistLeg & 1185 & $\mathrm{~mm}$ & $1185 \mathrm{~mm}$ & Leg center to center distance \\
\hline DistYoke & 1980 & $\mathrm{~mm}$ & $1980 \mathrm{~mm}$ & Yoke center to center distance \\
\hline Stages & 49 & & 49 & Number of stages of leg cross-section \\
\hline ThickCore & 2 & $\mathrm{~mm}$ & $2 \mathrm{~mm}$ & Core thickness, only used for Stages = 1 \\
\hline WidthYoke & 0 & $\mathrm{~mm}$ & $0 \mathrm{~mm}$ & Yoke width, =0 for same cross-section as leg's \\
\hline InfoCore & 0 & & 0 & 0: whole core: 1: legs only; 2: yokes only. \\
\hline
\end{tabular}

Figure 4. The window with the geometric features of the core The designed core models are given in Figure 5.
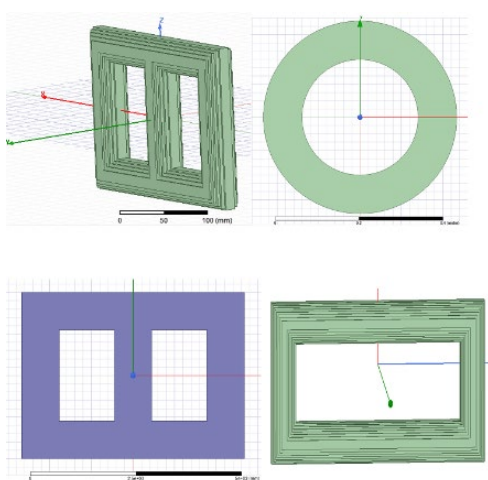

Figure 5. Designed core models

\subsection{Design of windings}

Transformers use concentrated winding type and hence the winding factor $k w=1$. It is known that each limb of the core will need to carry three coils and thus three terminals. This is why the coils and terminals are designed for three legs respectively. Similar to the core, the windings are designed in the order given below. First, the windings are selected from the menu and then the geometric properties of the windings are determined in the window that opens. Draw> User Define Primitive> RmExpert> Transcoils is selected respectively. The screen where winding properties are defined is given in Figure 6. The windings designed are given in Figure 7.

\begin{tabular}{|c|c|c|c|c|}
\hline Name & Value & Unit & Evaluated Value & Description \\
\hline Command & CreateUserDefinedPart & & & \\
\hline Coordinate Sys. & Global & & & \\
\hline Name & RMxprt/TransCoilddll & & & \\
\hline Location & syslib & & & \\
\hline Version & 6.0 & & & \\
\hline Distleg & 100 & $\mathrm{~mm}$ & $100 \mathrm{~mm}$ & Leg center to center distance \\
\hline Coiltype & 2 & & 2 & Coil type: 1 for solenoid coil; 2 for pancake coil \\
\hline Widthln & 42 & $\mathrm{~mm}$ & $42 \mathrm{~mm}$ & Coil width between two inner sides \\
\hline Depthln & 42 & $\mathrm{~mm}$ & $42 \mathrm{~mm}$ & Coil depth between two inner ends \\
\hline Radiusin & 21 & $\mathrm{~mm}$ & $21 \mathrm{~mm}$ & Coil inner fillet radius \\
\hline ThickCoil & 10 & $\mathrm{~mm}$ & $10 \mathrm{~mm}$ & Coil thickness of one side \\
\hline HighCoil & 96 & $\mathrm{~mm}$ & $96 \mathrm{~mm}$ & Coil height \\
\hline Layers & 10 & & 10 & Number of layers \\
\hline GapLayer & 3 & $\mathrm{~mm}$ & $3 \mathrm{~mm}$ & Gap between two layers \\
\hline InfoCore & 0 & & 0 & 0 : all coils: 1 : one coil only. \\
\hline
\end{tabular}

Figure 6. The window with the geometric features of the windings

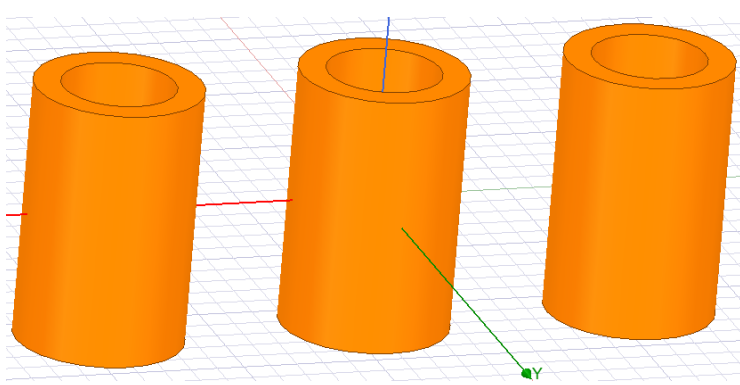

Figure 7. 3D model of designed windings 


\subsection{Determination of transformer terminals}

After the windings are designed, low voltage (LV_A, LV_B, and LV_C) or high voltage (HV_A, HV_B, and $\mathrm{HV}_{-} \mathrm{C}$ ) objects are selected by holding down the Ctrl key to form the coil terminals of a three-phase (for example A, B, C) transformer. After selecting the windings, the terminals of the windings are created with the option Modeler> Surface Section in the main menu. Later, terminals are defined as given in Figure 8. The process flow is like this; Modeler> Boolen> Separate Bodies.
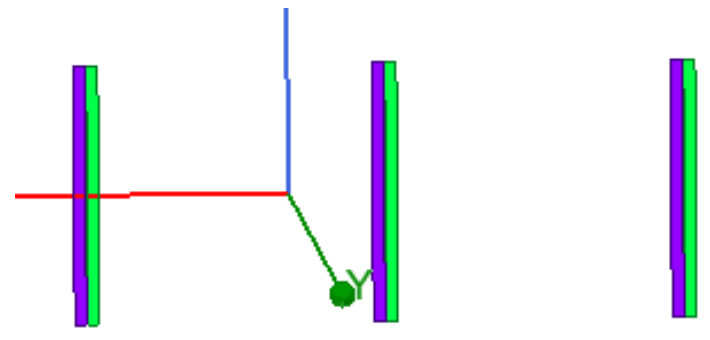

Figure 8. 3D model of designed windings

\subsection{Determining the type of solvent}

In the ANSYS @ MAXWELL program, there are a total of six different analysis types - three types of electricity and three types of magnetic solvents. In the studies, analyzes were carried out with the magnetic field transient regime solvent type. In the transient solvent type, constant-current or voltage can be supplied to the circuit with the help of an internal or external source.

A brief description of these solvent types can be made as follows.

Magnetic Numerical Decoders

- Magnetostatic Solver

It dissolves static magnetic fields caused by DC currents and permanent magnets. It can solve both linear and nonlinear materials. - Eddy Current Solver

It resolves magnetic fields that change sinusoidally in the frequency domain. Solves both Linear and Non-Linear materials (generates energy equivalent sinusoidal fields). It takes into account the displacement currents. Stimulated areas such as skin and current proximity effects are also considered.

- Transient Magnetic

It dissolves temporary magnetic fields caused by electric sources and permanent magnets that change or move over time in linear or nonlinear materials. Stimulated areas such as skin and current proximity effects are considered.

Electric Solvents

- Electrostatic Solver

Solves Static Electric Fields in linear materials.

- DC Conduction

It solves voltage, electric field, and current density from potential. It can also resolve electric fields in insulators.

- AC Conduction (2D only)

It resolves sinusoidally changing electric fields in the frequency domain. Can only be used with a 2D solver.

- Transient Electric

Transient electric fields are caused by time-varying voltages, charge distributions, or existing excitations in inhomogeneous materials. Electric potential is the amount of solution.

\subsection{Determining material for cores and coils}

It is necessary to define the type of vacuum zone and the materials that make up the cores and windings of the designed model. "Assign Material" is used to assign the materials used in the design. Material assignment for windings or core can be made to "View / Edit Material" or "Add Material" options from the library of the program.

In this paper, copper was chosen as the winding material. M125-027S laminated steel is used as the core material of transformers. Since the core material is not included in the library of the program, it has been transferred from an external library to the program environment. Similarly, to obtain the power loss value of the core, a file named "Core_Loss" with an extension of "* .tab" was called-used in the program. B-H and B-P curves of the material used are given in Figure 9.
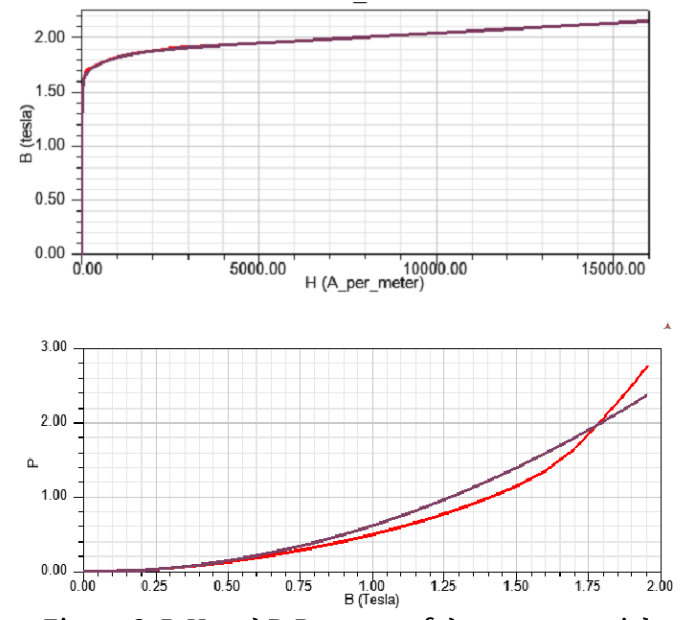

Figure 9. B-H and B-P curves of the core material

In designs made with ANSYS@MAXWELL program, the core loss coefficients $\mathrm{K}_{\mathrm{h}}, \mathrm{K}_{\mathrm{c}}$, and $\mathrm{K}_{\mathrm{e}}$ values of the material used as core material vary depending on the frequency and thickness of the lamination. Specific core losses of materials used for $50 \mathrm{~Hz}$ frequency are presented in Figure 10.

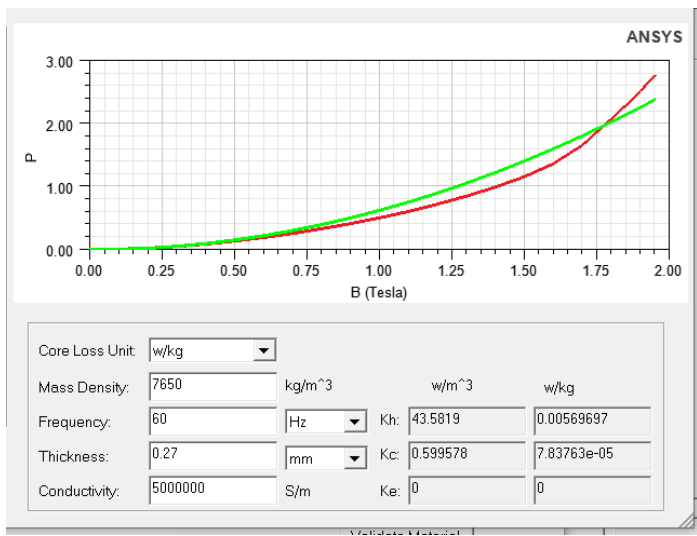

Figure 10. Properties of transformer core material

\subsection{Mesh settings of the model}

According to the model designed in ANSYS @ MAXWELL program, a network is automatically generated by the program. After the network is created, a field-solution-is calculated for each model. The network created automatically for the designed model is generally not sufficient for a realistic analysis result. For a closer analysis of real values, each element is divided into a small region, and the correct solution is approached by increasing the mesh number. As the mesh number of the model increases, the results of the simulation obtained from the analysis become very realistic. The disadvantage of increasing the number of networks is that it increases the analysis time. In Figure 11, a designed model and mesh examples of the model are given.
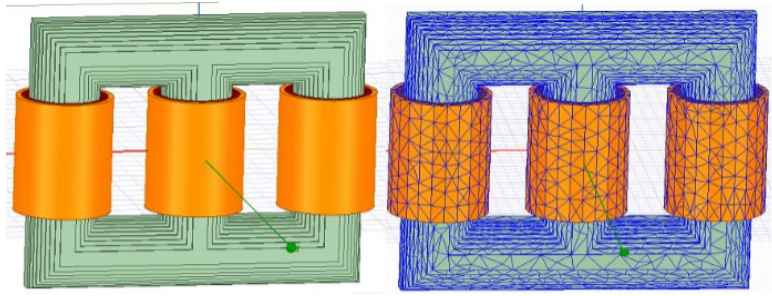

Figure 11. Mesh of the transformer model 


\section{Transformer's magnetic field and loss analysis}

Electromagnetic field analysis, loss values, and electromagnetic forces in the windings of the transformer designed in this section are obtained for the steady-state condition. For analysis, a voltage stimulation that is given in Figure 12 and increases exponentially has been given to the program [11-12].

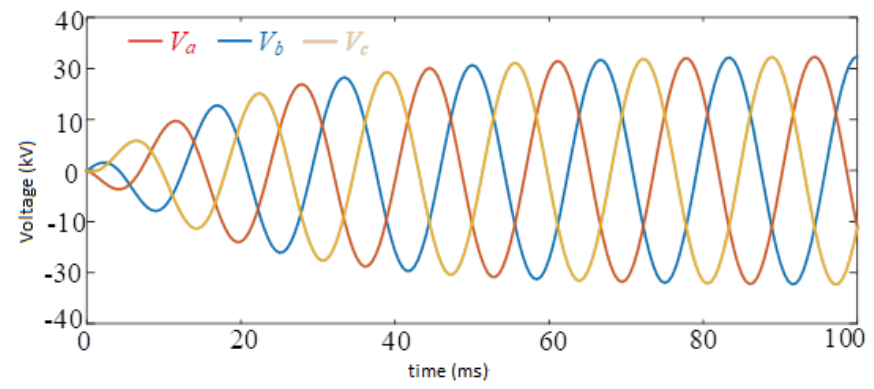

Figure 12. The input voltage of the transformer.

In the program, the boundary conditions of the transformer model, geometric dimensions, and properties of all materials used are defined on the model. The electrical information used in the analysis of the transformer is presented in Table 1.

Table 1. Transformer properties

\begin{tabular}{ll}
\hline Parameter & Value \\
\hline Rating power & $15 \mathrm{MVA}$ \\
HV voltage & $33 \mathrm{kV}$ \\
LV voltage & $11 \mathrm{kV}$ \\
Core loss & $12.5 \mathrm{~kW}$ \\
Copper loss & $97 \mathrm{~kW}$ \\
Frequency & $50 \mathrm{~Hz}$ \\
Core material & $\mathrm{M} 125-027 \mathrm{~S}$
\end{tabular}

The magnetic flux distribution of the transformer modeled in ANSYS @ Maxwell 3D environment is given in Figure 13.

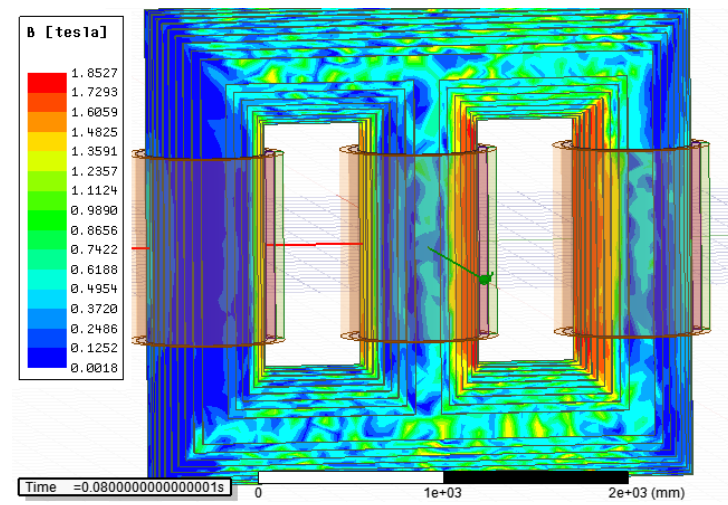

Figure 13. Magnetic flux distribution on transformer core.

Magnetic field strength was also obtained from the analysis in the study. The magnetic field at the core was strong and is presented in Figure 14. The strains in the windings can be seen from the field intensity distribution. Difficulties have occurred in the winding insulation, especially in the third phase. Excessive strain may cause the insulation material to deteriorate or even perforate.

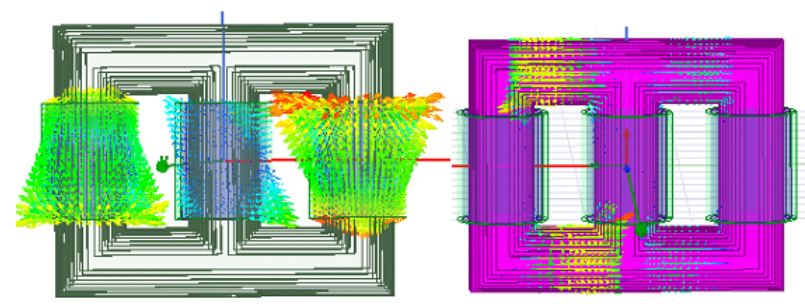

Figure 14. The magnetic field intensity distribution

The core loss curve of the modeled transformer obtained with ANSYS@Maxwell is presented in Figure 15.

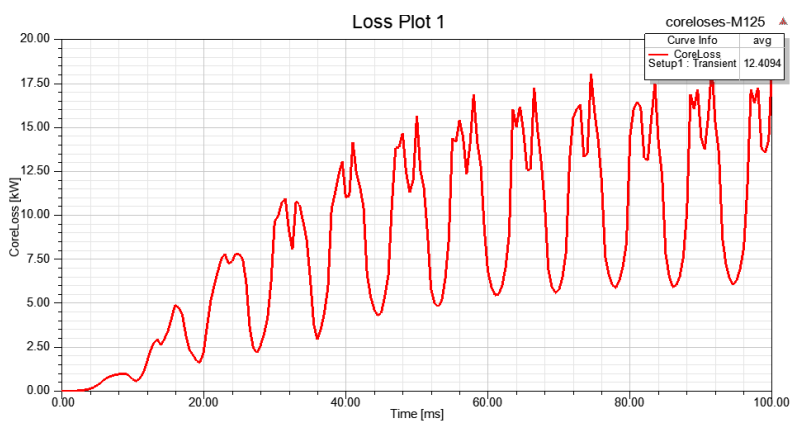

Figure 15. Core loss

\section{Conclusion}

In this paper, the structural analysis of the transformer was made in three dimensions with ANSYS @ Maxwell program. This study, it is aimed to reduce the number of prototypes of transformer designers and manufacturers and to reduce the cost. For this purpose, the values of the transformer designed by using the real values of the transformer were very close to the values of the real transformer. This situation reveals the accuracy and reliability of the method used. The main purpose of this study is to reduce the cost of materials, to reduce the number of prototypes produced for experimental purposes, and to obtain the optimum model of the desired models. The method and analysis program used gave results with sufficient accuracy to verify the designed models.

\section{Declaration of Conflict of Interests}

The author declares that there is no conflict of interest. They have no known competing financial interests or personal relationships that could have appeared to influence the work reported in this paper.

\section{References}

[1.] Heatcote M, J\&P Transformer Book. Thirteenth Edition, Oxford, United Kingdom, Newness An imprint on Elsevier (2007).

[2.] Turan H, Çekirdekli D Hava Aralığı Bulunan Reaktör Çeşitlerinin İrdelenmesi ve Bir Prototip için Uygulama Örneği. Yüksek Lisans Tezi, Kocaeli Üniversitesi, Kocaeli, Türkiye, (2007).

[3.] Dönük A, Modeling and Design of Iron-Core Shunt Reactors With Discretely Distributed Air-Gaps. Doktora Tezi, ODTÜ, Ankara, Turkey, (2012).

[4.] Zheng $\mathrm{T}$, Zhao YJ, Ying J, Chen PL, Zhang FF "Design and analysis on the turn-to-turn fault protection scheme for the control winding of a magnetically controlled shunt reactor". IEEE Transactions, 30(2), (2015), 967-975. 
[5.] Wojda R.P, Kazimierczuk, M.K "Analytical winding size optimization for different conductor shapes using Ampère's Law", Power Electronics, IET, 6 (6), (2013), 1058-1068.

[6.] Özüpak Y, MAMIS M. S Realization of electromagnetic flux and thermal analyses of transformers by finite element method. IEEJ Transactions on Electrical and Electronic Engineering, 14(10), (2019), 1478-1484. Doi: 10.1002/tee.22966.

[7.] Özüpak Y, MAMIS M. S, TEKE İ. H Electromagnetic Field and Total Loss Analysis of Transformers by Finite Element Method. International Journal of Engineering And Computer Science, 8(1), (2019), 24451-24460. (Yayın No: 5774086)

[8.] Yazdani-Asrami M, Mirzaie M, Akmal A. S No-load loss calculation of distribution transformers supplied by nonsinusoidal voltage using three-dimensional finite element analysis, Energy, vol. 50, no. 1, (2013), pp. 205-219.

[9.] M. Ostrenko and B. Andriienko, "Transformer impulse surges calculation by FEM coupled to the circuit," in IEEE Transactions on Magnetics, vol. 53, no. 6, pp. 1-4, June (2017), Art no. 7401804.

[10.] T. Zupan, B. Trkulja, R. Obrist, T. Franz, B. Cranganu-Cretu, and J. Smajic. Transformer windings rlc parameters calculation and lightning impulse voltage distribution simulation. IEEE Transactions on Magnetics, 52(3):1-4, March (2016).

[11.] Wojda R.P, Kazimierczuk, M.K, Analytical winding size optimization for different conductor shapes using Ampère's Law", Power Electronics, IET, 6 (6), (2013),"1058-1068.

[12.] Yugendra Rao K N, Dynamic Modeling and Calculation of Self and Mutual Inductance between a Pair of Coils for Wireless Power Transfer Applications using ANSYS Maxwell, International Advanced Research Journal in Science, Engineering and Technology Vol. 2, Issue 10, (2015.

\section{How to Cite This Article}

Özüpak Y., Performing Structural Design and Modeling of Transformers Using ANSYS-Maxwell, Brilliant Engineering, 2(2021), 38-42. https://doi.org/10.36937/ben.2021.002.005 